\title{
NILAI-NILAI EDUKATIF LAGU JASO MANDEH UNTUK MEMBANGUN KARAKTER PESERTA DIDIK (Suatu Analisis Hermeneutik)
}

\author{
Desyandri \\ Universitas Negeri Padang, Indonesia \\ E-mail. desyandri@fip.unp.ac.id
}

\begin{abstract}
Abstrak
Artikel ini bertujuan untuk menemukan, menginterpretasikan, dan mengidentifikasikan nilai-nilai edukatif yang terkandung dalam lagu Jaso Mandeh ciptaan Nuskan Syarif. Proses identifikasi dilakukan dengan analisis hermeneutik secara multidisipliner. Interpretasi dihasilkan dengan mengaitkan pada aspek kebahasaan, musik/lagu, psikologi, sosio-kultural, dan pendidikan, sehingga dapat diidentifkasi 5 (lima) nilai-nilai edukatif, yaitu Syarak/Agamo, cinto ranah Minang, kesabaran, keikhlasan, dan keteguhan hati. Nilai-nilai edukatif tersebut merupakan sarana untuk mengedukasi peserta didik agar melakukan tindakan dan perilaku yang mencerminkan selayaknya orang Minang. Pendidikan dan pembelajaran sebagai sarana pewarisan budaya berkewajiban untuk mengeksplorasi, mensosialisasikan, mengaktualisasikan, dan membudayakan nilai-nilai edukatif secara berkelanjutan agar terciptanya peserta didik yang beradat, beradab, dan berkarakter mulia.
\end{abstract}

Keywords: adat, values, lagu, edukatif, pendidikan, karakter, hermeneutik

\section{Educational Values of Jaso Mandeh Song for Student Character Building (A Hermeneutic Analysis)}

\section{Desyandri \\ PGSD FIP UNP}

E-mail. desyandri@yahoo.co.id

\begin{abstract}
This article aims to discover, interpret, and identify the educational values embodied in the song of Jaso Mandeh creation by Nuskan Syarif. The identification process is done by a multidisciplinary hermeneutic analysis. Interpretation is generated by associating the aspects of language, music/songs, psychological, socio-cultural, and educational, so it can be identified five (5) educational values, namely Syarak/agamo, love the realm of Minang, patiance, sincerity, and courage. The educational values is a means to educate learners to perform the actions and behaviors that reflect proper Minang people. Education and learning as a means of cultural inheritance are obliged to explore, socialize, actualize, and cultivate the educational values on an ongoing basis in order to create learners who are well-mannered, civilized and noble character.
\end{abstract}

Keywords: custom, values, song, educational, education, character, hermeneutic

\section{A. PENDAHULUAN}

Salah satu jenis kesenian yang ada di Minangkabau adalah lagu Minang atau dikenal juga dengan sebutan lagu Minang. Lagu Minang, khususnya lagu Minang lamo merupakan ungkapan perasaan dan pemikiran seniman/pencipta lagu Minang yang dituangkan ke dalam bentuk karya musik, yakni lagu-lagu Minang.

$$
\sim 738 \sim
$$

Artikel disajikan pada International Seminar on Education ( $2^{\text {nd }}$ ISE) FIP UNP berkolaborasi dengan Institut Pendidikan Guru Kampus Pendidikan Teknik Malaysia. October, 20-21 $1^{\text {th }}$, 2016, Padang, Sumatera Barat

Theme: "Understanding Future Trends Toward Global Education" 
Lagu-lagu Minang tersebut sarat nilainilai atau pesan yang ingin disampaikan oleh pencipta lagu terhadap masyarakat penikmat atau pendengar. Selain berisikan nilai-nilai, lagu Minang juga menggambarkan kondisi realitas sosial-budaya yang terjadi di masyarakat.

Kandungan nilai-nilai atau pesan yang terdapat pada lagu Minang dapat dijadikan sebagai salah sarana terhadap proses aktualisasi nilai-nilai adat Minangkabau bagi masyarakat yang bermuara pada pembangunan karakter masyarakat Minangkabau yang beradat dan berbudaya. Nilai-nilai tersebut dijadikan sebagai pedoman dalam melahirkan tindakan dan perilaku masyarakat Minang yang berkarakter mulia. bahwa:

Barendregt (2002: 416) mengatakan

Minang songs, provides one of the avenues through which identification as Minangkabau is experienced, defined, and consumed internally. It constructs a Minangkabau sensibility "by depicting a recognizable landscape through the use of metaphors" related to migration and the homeland.

Lagu Minang mengidentifikasikan adat budaya Minangkabau yang dianut, didefinisikan, dan dikonsumsi secara internal serta dapat membangun perasaan tentang keindahan alam yang dapat dikenali melalui penggunaan metafora terkait dengan ranah Minang dan kebiasaan atau tradisi merantau. "The attachment goes beyond this landscape to "a community sharing the same moral values" (ibid.:417). Lirik lagu dapat digunakan sebagai sarana mengarahkan tindakan menuju pada solusi terhadap permasalahan yang mengganggu masyarakat. Meskipun hal ini dapat berbentuk ejekan dan perasaan malu, atau tindakan sanksi hukum, dan teks-teks lagu memberikan rilis psikologis. Kebebasan berekspresi diperbolehkan dalam lagu, lirik sebagai sarana yang sangat baik untuk penyelidikan terhadap proses psikologis individu dan masyarakat dalam suatu budaya.
Hal tersebut senada dengan pendapat Hajizar (2012) yang menyatakan bahwa lagulagu Minang berangkat dari resepsi nilai-nilai sosial masyarakat. Dengan demikian, lagu-lagu Minang dapat digambarkan sebagai sebuah keintiman atau kedekatan dengan budaya Minangkabau, seperti yang dikemukakan Fraser (2011), "Minang songs is a form of cultural intimacy, one that allows the Minangkabau to recognize themselves within the nation as distinct from its other constituents".

Nilai-nilai tersebut sangat penting diaktualisasikan dalam proses pendidikan dan pembelajaran di sekolah menuju pembangunan karakter peserta didik. Pendidikan sebagai proses pembudayaan bukan hanya merupakan proses transformasi pengetahuan yang terfokus pada penguasaan kemampuan intelektual semata, tetapi juga berperan mewariskan nilainilai positif budaya dan kearifan lokal sebagai tuntunan dalam melahirkan tindakan dan perilaku. Dengan kata lain, pendidikan seharusnya berupaya menjadikan nilai-nilai edukatif adat Minangkabau dan lagu-lagu Minang sebagai pedoman untuk melahirkan tindakan dan perilaku peserta didik. Upaya pembudayaan tersebut dapat dijadikan sebagai sarana untuk menumbuhkan dan membangun karakter peserta didik. Pendidikan dapat melahirkan peserta didik yang me- miliki pengetahuan luas dan berkarakter, baik ketika berada di lingkungan sekolah maupun dalam (Desyandri, 2015).

Ditinjau dari tujuan pendidikan, Tilaar (2010: 20-21) mengemukakan bahwa tujuan pendidikan bukan hanya manusia yang terpelajar tetapi manusia yang berbudaya, sehingga pendidikan dapat berfungsi sebagai proses pemberdayaan dan proses pembudayaan. Pendidikan sebagai proses pemberdayaan dan pembudayaan mengisyaratkan bahwa pendidikan memiliki tugas menumbuhkembangkan nilai-nilai positif yang terkandung dalam sebuah kebudayaan.

Realita yang terjadi di lapangan terlihat bahwa proses pendidikan belum optimal dan lebih berorientasi pada penguasaan kemampuan intelektual semata, mengabaikan 
proses pelestarian dan aktualisasi nilai-nilai adat Minangkabau dan nilai-nilai edukatif yang terkandung dalam lagu-lagu Minang, sehingga pendidikan hanya dijadikan sebagai alat untuk memperkaya pengetahuan tetapi miskin nilainilai. Tilaar (2010: 218) mengemukakan bahwa intelektualisme yang telah menjadi ciri pendidikan nasional telah mengasingkan budaya dan apresiasi budaya dalam pendidikan nasional. Bukan berarti bahwa kognisi tidak diperlukan dalam pengembangan kepribadian manusia.

Pandangan Tilaar terlihat dalam realita pembelajaran pendidikan seni musik di sekolah-sekolah. Pembelajaran didominasi fungsi hiburan semata, pemberian materi dalam bentuk hafalan musik/lagu-lagu Minang, mengekplorasi kandungan nilai-nilai edukatif secara garis besar tanpa dilanjutkan dengan pengimplementasian dan pembudayaan nilainilai tersebut dalam kehidupan sehari-hari peserta didik. Di sisi lain, sekolah terlihat mulai meninggalkan lagu Minang, sehingga nilainilai edukatif yang terkandung dalam lagu-lagu tersebut tidak lagi difungsikan sebagaimana mestinya. Hal ini dapat dibuktikan dengan sedikitnya lagu Minang yang dibelajarkan di sekolah dan kebanyakan peserta didik kurang mengetahui lagu Minang salah satunya adalah lagu Jaso Mandeh. Seharusnya pendidikan seni musik dapat mengembangkan rasa keindahan, kreativitas, dan kepribadian, serta menjadikan peserta didik lebih produktif dan berbudaya (Astuti: 2010: 5). Pembelajaran tentang lagu Minang dapat mengedukasi peserta didik untuk mengetahui kekhasan dan rasa cinta terhadap ranah Minang.

Kurang optimalnnya penanaman nilainilai yang terkandung dalam lagu Minang berakibat munculnya kecenderungan perilaku dan karakter peserta didik yang tidak beradat/tidak beradab, seperti: kurangnya rasa menghargai dan menghormati orang lain, kurangnya sopan-santun, lebih mementingkan diri sendiri, serta kurang peduli dengan adat atau budaya daerah mereka sendiri. Perilaku negatif ini, jika dibiarkan terus-menerus mengakibatkan tercerabutnya peserta didik dari budayanya sendiri. Orang Minang yang tidak tahu dengan adat Minangkabau. Seperti kata pepatah Minang, "Lah lupo kacang jo kuliknyo", maksud pepatah ini menggambarkan seseorang yang telah lupa dengan adat budayanya sendiri (Desyandri, 2015).

Permasalahan memudarnya nilai-nilai adat Minangkabau dan perkembangan ilmu pengetahuan, teknologi, dan seni (IPTEKS) melaju dengan cepat tanpa diikuti dengan perubahan sosial-budaya yang cepat pula, sehingga dampak yang muncul dapat ditengarai bahwa proses pendidikan dan keragaman budaya tidak lagi menunjukkan peran pentingnya dalam membangun per- adaban bangsa (Desyandri, 2014). Mengingat pentingnya nilai-nilai edukatif yang terkandung dalam lagu Minang sebagai sarana untuk membendung perilaku peserta didik yang mengarah pada hal-hal negatif dan sekaligus sebagai upaya membangun karakter peserta seharusnya mendapat perhatian yang serius diperlukan upaya mengangkat dan mementingkan kembali (merevitalisasi) nilainilai edukatif lagu Minang (Desyandri, 2016). Salah satunya dengan melakukan kajian dan penelitian mendalam tentang nilai-nilai edukatif lagu Minang, diantaranya lagu Jaso Mandeh ciptaan Nuskan Syarif.

\section{B. METODE PENELITIAN}

Metode penelitian menggunakan analisis hermeneutik, seperti yang diungkapkan Fithri (2013: 64-74) mengutip pendapat Ricoeur yang bahwa unsur-unsur dan penerapan teori hermeneutik, yaitu 1) objektivikasi struktur teks: hermeneutik tidak mencari kesamaan maksud dengan pengarang teks, tetapi menafsirkan makna teks secara objektif sesuai dengan yang diisyaratkan teks, 2) distansiasi (perjarakan): jalan utama menuju otonomi teks, 3) apropriasi: menjadikan sesuatu yang sebelumnya "asing" kemudian menjadi "milik sendiri" dan bertujuan untuk mengaktualkan makna teks bagi pembaca terkini dan 4) analogi permainan: teks menjadi lebih lentur dan memungkinkan kreativitas penafsir untuk menemukan makna-makna baru.

Desyandri (2015: 126-141) mengemukakan bahwa analisis hermeneutik, terutama unsur analogi permainan dapat 
dikembangkan menjadi analisis hermeneutik multidisipliner dengan mengaitkan proses interpretasi pada beberapa aspek, yaitu aspek kebahasaan, musik/lagu, psikologi, sosiokultural, dan pendidikan. Dengan demikian, proses analisis dapat menghasilkan penafsiran yang lebih kaya dan dapat dipahami dengan mudah oleh pembaca.

\section{PEMBAHASAN}

Lagu Jaso Mandeh diciptakan oleh Nuskan Syarif dan dipopulerkan oleh Tiar Ramon pada era tahun 1980-an. Lagu tesebut merupakan lagu yang melegendaris di kalangan masyarakat Minangkabau, bahkan juga digunakan atau dibelajarkan di sekolahsekolah, seperti sekolah dasar.

Secara garis besar menggambarkan tentang jasa seorang ibu mulai masa kehamilan sampai melahirkan seorang anak dan jasa tersebut tidak akan pernah terbalas oleh anaknya, walaupun diganti dengan harta yang berlimpah.

1. Aspek Kebahasaan

Kalimat lagu, "Sambilan bulan sapuluah hari". Secara denotasi memiliki makna sebagai perhitungan lamanya waktu yang dibutuhkan dalam sebuah aktivitas atau pekerjaan, yaitu hingga sambilan (sembilan) bulan ditambah sapuluah (sepuluh) hari, sedangkan secara konotasi memiliki makna yang menunjukkan: 1) sebuah perjalanan waktu yang lama, dan 2) usia kehamilan seorang ibu. Usia kehamilan selama sembilan bulan sepuluh hari tersebut memiliki konsekuensi terhadap munculnya berbagai permasalahan atau penderitaan (manangguang ragam) yang harus dijalani oleh seorang ibu, sehingga tiada upaya lain yang mesti dilakukan selain bersabar menanti (saba mananti).

Secara denotasi kalimat tersebut hanya bermakna sederhana, yakni permasalahan berjalannya waktu dan harus bersabar menjalaninya, sedangkan secara konotasi makna kalimat tersebut menjadi lebih luas. Pada masa kehamilan, seorang ibu merasakan susah-payahnya mengandung anak dan harus menjalani beberapa rintangan, seperti: 1) susah makan dan sering mual dan mules, 2) membawa jabang bayi dalam kandungan yang semakin lama semakin besar dan makin bertambah berat, 3) harus berhati-hati dalam melakukan aktivitas sehari-hari agar jabang bayi tidak terganggu, 4) harus memeriksakan kehamilan secara berkala agar jabang bayi tetap sehat, dan 5) di samping menjaga kesehatan jabang bayi, seorang ibu juga menyiapkan diri agar selalu sehat dan memakan makanan yang bergizi.

Kalimat berikutnya, "Manyabuang nyao basarah diri, darah tatumpah manyiram bumi" merupakan kalimat yang memiliki makna konotasi. Kalimat tersebut memiliki makna sebagai puncak penderitaan seorang ibu dalam proses melahirkan anak dan ketika usia kandungan sudah sampai waktunya (sembilan bulan sepuluh hari), seorang ibu akan merasakan betapa susah dan sakitnya proses melahirkan anak. Ibu berada pada kondisi mempertahankan nyawanya (manyabuang nyao), hidup atau mati, menahan sakit yang tidak tertanggungkan, dan oleh karena begitu susah dan sakitnya proses melahirkan tersebut maka seorang ibu hanya berdo'a dan berserah diri (basarah diri) pada yang kuasa (Tuhan Yang Maha Esa) agar diberikan kemudahan dalam melahirkan anak, dan akhirnya berujung dengan keluarnya darah (darah tatumpah manyiram bumi).

Ketika lahirnya seorang anak ke muka bumi, dan pertama kali mendengar rengekan atau tangisan (jolong tadanga rengek jo tangih), maka seorang ibu telah melawati masa kritisnya dan terobatilah semua penderitaan (barubek jariah) yang dilaluinya selama sembilan bulan sepuluh hari berakhir dengan perasaan senang (sananglah hati). Ibu merasakan sesuatu yang sangat menyejukkan dan menyenangkan jiwa, yakni kelahiran seorang anak.

Kalimat selanjutnya menyatakan bahwa, "Anggak ka ameh babungkahbungkah, anggak ka perak indak tabilang". Secara denotasi mempunyai makna yang 
menjelaskan tentang walaupun (anggak) logam mulia atau emas (ameh) yang bebongkah-bongkah (babungkah-bungkah) dan walaupun (anggak) perak (perak) yang sangat banyak jumlahnya (indak tabilang). Kalimat isi dijelaskan pada kalimat ketiga dan keempat, lirik lagu yang menyatakan bahwa, "Kok hati mandeh nan dilukoi". Kalimat tersebut secara denotasi bermakna hanya sebatas melukai hati ibu, sedangkan secara konotasi bermakna bahwa jangan pernah berniat untuk melukai hati seorang ibu, karena di dalam ajaran Islam dinyatakan bahwa rido Allah terletak di rido kedua orang tua.

Hadis Abdullah ibnu Umar tentang rido Allah terletak pada rido kedua orang tua yang artinya, "dari Abdullah bin "Amrin bin Ash r.a berkata, Nabi Muhammad SAW telah bersabda, "Keridoan Allah itu terletak pada keridoan orang tua, dan murka Allah itu terletak pada murka orang tua". (H.R. At-Tirmidzi). Hadis ini dinilai shahih oleh Ibnu Hibban dan Al-Hakim). Jika hati seorang ibu dilukai (kok hati mandeh nan dilukoi) memiliki konsekuensi terhalangnya rido Allah terhadap anak berbuat demikian. Perbuatan melukai hati seorang ibu mengakibatkan “'Arsy baguncang”. Secara denotasi kata 'Arsy memiliki makna sebagai makhluk tertinggi, berupa singgasana seperti kubah yang memiliki tiang-tiang yang dipikul oleh malaikat. Dengan kata lain, jika seorang anak melukai hati orang tua, bukan hanya akan menghalangi rido Allah akan tetapi berakibat terhadap kemurkaan Allah.

Kemurkaan Allah dapat berakibat buruk terhadap anak yang melukai hati seorang ibu dab sekaligus sebagai pertanda (alamaik) hidup (hiduik) seseorang tidak akan berjalan dengan baik atau tidak akan tenang (tak kan salasai). Jika hal ini terjadi, tidak ada artinya seseorang itu hidup di muka bumi, seperti ungkapan pepatah Minangkabau yang menyatakan, "Bak cando kayu digiriak kumbang". Secara denotasi pepatah tersebut memiliki makna seperti pohon atau kayu (bak cando kayu) yang dilobangi (digiriak) oleh binatang, seperti kumbang (kumbang). Kondisi ini mengakibatkan pohon atau kayu tersebut akan terganggu proses pertumbuhannya. Secara konotasi pepetah tersebut memiliki makna yang menggambarkan akibat buruk yang dihadapi seorang anak yang durhaka atau menyakiti hati orang tua (ibu).

Kalimat selanjutnya menyatakan bahwa, "Jaso mandeh indak ka tabaleh, bia babungkah ameh jo perak". Secara denotasi kata jaso mandeh (jasa ibu) memiliki makna segala sesuatu upaya yang dilakukan oleh orang tua dalam membesarkan dan menjaga anaknya, jasa tersebut tidak dapat dibalas walaupun dengan emas dan perak. Secara konotasi jaso mandeh (jasa seorang ibu) memiliki makna sebagai pertolongan yang dilakukan seorang ibu terhadap anaknya. Pertolongan tersebut dipenuhi dengan berbagai rintangan berat bahkan dilewati dengan susah-payah, sampai menumpahkan darah, pertaruhan nyawa (hidup atau mati), semua itu tidak akan terbalas oleh seorang anak walaupun dibayar menggunakan harta benda yang berlimpah ruah.

2. Aspek Musik

Lagu Jaso Mandeh menggunakan 5 jenis interval, yakni 1) interval prime sebanyak 29 buah, 2) interval seconde sebanyak 112 buah, 3) interval ters sebanyak 33 buah, 4) interval kwart sebanyak 3 buah, dan 5) interval kwint sebanyak 3 buah. Secara keseluruhan dapat dikemukakan bahwa perjalanan melodi didominasi interval seconde, dengan kata lain perjalanan melodi lagu dapat dikatakan melangkah yang terdapat pada birama 27 sampai dengan birama 34 , seperti notasi berikut:

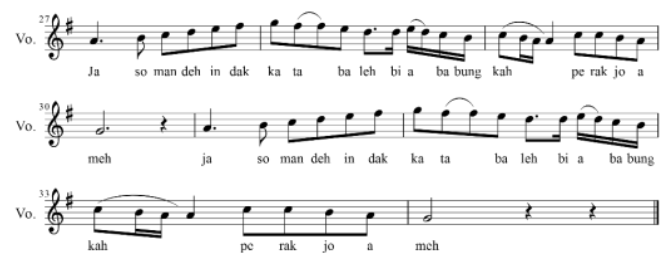

Transkripsi: Desyandri

\section{Notasi 1 \\ Gerak Melodi Melangkah Lagu Jaso Mandeh}


Galitiak (cengkok) Minang dapat dilihat dari keseluruhan perjalanan melodi lagu Jaso Mandeh, akan tetapi berikut ini ditunjukkan beberapa karakteristik tersebut, diantaranya potongan melodi pada birama 5 sampai dengan birama 9 dan birama 27 sampai dengan birama 30. Galitiak Minang tersebut dapat dilihat potongan notasi lagu yang terdapat pada gambar di bawah ini:

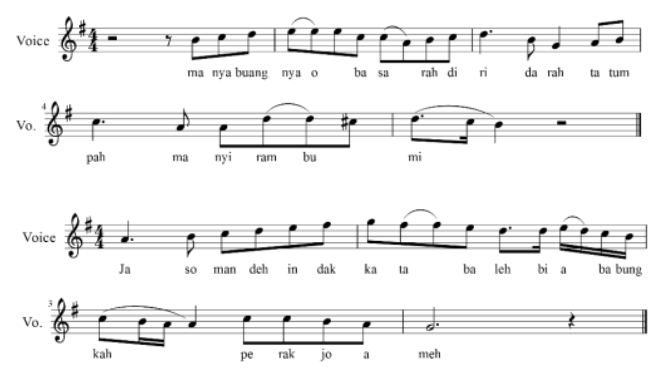

Transkripsi: Desyandri

Notasi 2

\section{Galitiak (Cengkok) Minang Lagu Jaso Mandeh}

Pola irama khas yang terdapat pada musik iringan lagu Jaso Mandeh memiliki kemiripan dengan kebanyakan pola irama lagu-lagu Minang yang bertempo lambat, seperti pola irama lagu Minangkabau dan lagu Lintuah. Selain pola irama khas Minang dan tempo lagu yang berhubungan dengan perlambangan suasana kampung halaman yang tentang, tenteram, damai, adil, dan harmonis, elemen berikutnya adalah jangkauan nada (ambitus) yang terdapat pada lagu Jaso Mandeh.

Ambitus lagu Jaso Mandeh berkisar antara nada D (5,) sampai dengan nada G' (1'). Ambitus lagu Jaso Mandeh berjarak 1 $1 / 2$ oktaf (sebelas nada) dan tergolong pada jangkauan nada yang pendek dan tidak terlalu susah untuk dinyanyikan, serta sangat berpengaruh terhadap ekspresi seseorang ketika menyanyikan lagu tersebut. Jangakauan nada tersebut menggambarkan bahwa lagu Jaso Mandeh merupakan lagu sederhana yang mudah diingat atau dihafalkan, sehingga memudahkan seseorang dalam proses pengekspresiannya. Hal ini sangat berkaitan dengan faktor kebertahanan dan dan kepopuleran lagu Jaso Mandeh sampai dewasa ini.

Kebertahanan dan kepopuleran lagu

Jaso Mandeh hingga dewasa ini menandakan bahwa lagu tersebut disukai dan diminati oleh para pendengar atau penikmat lagu, serta nasehat serta pesanpesan yang disampaikan berupa nilai-nilai dalam menghargai jasa-jasa ibu mulai dari masa kehamilan hingga melahirkan. Jasa tersebut tidak akan pernah terbalas oleh seorang anak, walaupun diganti dengan harta benda yang berlimpah-ruah, dan sebabtiasa dijadikan sebagai pedoman bagi seorang anak dalam menjaga dan melahirkan tindakan dan perilaku atau sikap yang selalu menghargai dan menghormati seorang ibu sebagai penerus keturunan menurut norma atau aturan adat budaya Minangkabau.

3. Aspek Psikologi

Suasana kejiwaan atau emosional yang dihadirkan atau dikomunikasikan dalam lagu Jaso Mandeh dapat diidentifikasi melalui penafsiran lirik dan latar belakang penciptaan lagu. Pencipta lagu berupaya untuk mengenalkan dan mengkomunikasikan suasana emosional yang dirasakannya bahkan perasaan semua orang yang ditujukan pada penyanyi/pemain musik dan pendengar atau penikmat lagu. Suasana emosional tersebut adalah rasa untuk menghormati dan menghargai jasa-jasa seorang ibu yang tak terhingga, seperti ungkapan, "Kasiah ibu sapanjang jalan, kasiah anak sapanjang panggalan" maksudnya kasih sayang seorang ibu tak berujung atau tidak akan pernah terbalas oleh seorang anak, sedangkan kasih sayang seorang anak hanya sepanjang panggalan (galah). Pencipta lagu ingin membangkitkan rasa atau memberikan stimulasi suasana emosional bagi masyarakat Minangkabau agar senantiasa menghargai dan menghormati jasa-jasa seorang ibu.

Stimulasi tersebut dihadirkan dan dimunculkan dalam berbagai suasana, yaitu: 1) suasana susah payah yang dilalui seorang ibu; mengandung selama sembilan bulan 
sepuluh hari, menyabung nyawa dan berserah diri pada Yang Maha Kuasa, dan bersimbahkan darah, 2) suasana suka cita ketika lahirnya seorang anak yang dirindukan; terobati rasa susah payah yang telah dilalui selama masa kandungan, 3) ganjaran seorang anak yang melukai hati seorang ibu; bumi menyumpah, 'arasy berguncang, hidup seorang anak tidak akan tenang dan lancar (hidup seperti kayu yang dilobangi kumbang), dan 4) jasa-jasa ibu yang tidak terbalas walaupun diganti dengan emas dan perak yang berbungkahbungkah.

Paling tidak ada empat stimulasi yang dihadirkan dan dimunculkan oleh seniman atau pencipta lagu bertujuan untuk menggugah jiwa dan perasaan, serta memengaruhi perilaku pendengar atau penikmat lagu Jaso Mandeh untuk melakukan tindakan-tindakan dan perilaku yang senantiasa menghargai dan menghormati jasa-jasa seorang ibu. Upaya untuk melahirkan tindakan-tindakan dan perilaku tersebut merupakan nasehat atau pesan-pesan yang disampaikan seniman atau pencipta kepada pendengar atau penikmat lagu.

4. Aspek Sosiokultural

Mengacu pada hasil analisis aspek kebahasaan, aspek musik, dan aspek psikologi yang telah dipaparkan sebelumnya secara umum lagu Jaso Mandeh juga berkaitan erat dengan kondisi sosiokultural yang terjadi, berlaku, dan berkembang di lingkungan masyarakat adat budaya Minangkabau. Secara umum sumber ide dan topik yang dijadikan sebagai sarana dalam menciptakan lagu Jaso Mandeh oleh seniman atau pencipta lagu bersumber pada dua hal, yakni: 1) realitas sosial yang terjadi pada seorang anak yang cenderung tidak menghargai jasa-jasa ibu atau orang tua mereka pada hal, 2) kondisi ideal yang berlaku pada adat budaya Minangkabau yang senantiasa memposisikan seorang ibu atau kaum perempuan pada posisi yang agung dan penting yang dikenal dengan sistem kekerabatan matrilineal (keturunan di tarik melalui garis ibu).

Dua kondisi realitas sosial dan budaya yang terjadi di lingkungan masyarakat Minangkabau tersebut merupakan gambaran kesenjangan sosial budaya yang menyatakan bahwa realitas sosial seorang anak yang cenderung kurang menghargai jasa-jasa seorang ibu merupakan hal yang bertolak belakang dengan realitas budaya yang mengharuskan seorang untuk senantiasa menghargai jasajasa seorang ibu, apalagi dalam sistem kekerabatan matrilineal.

Kesenjangan tersebut diharapkan seniman atau pencipta lagu Jaso Mandeh sebagai stimulus dan upaya untuk memberikan kesadaran pada seorang anak agar menghargai dan menghormati ibu mereka, atau dengan kata lain kesenjangan realitas sosial dan budaya yang terjadi, berlaku, dan berkembang di lingkungan masyarakat Minangkabau secara tidak langsung turut memengaruhi pola pikir, tindakan dan perilaku anak-anak di Minangkabau agar menjadi anak yang berguna dan berbakti pada ibu atau orang tua mereka.

5. Aspek Pendidikan dan Nilai-nilai Edukatif Berdasarkan paparan interpretasi hermeneutik yang dilihat dari aspek kebahasaan, musik, psikologi, dan sosiokultural terhadap lagu Jaso Mandeh yang telah dikemukakan sebelumnya dapat ditafsirkan bahwa semestinya seorang anak senantiasa menghargai dan menghormati jasa-jasa seorang ibu agar dalam kehidupan mereka sehari-hari dapat berjalan lancar dan jauh dari murka Allah SWT, karena ridho Allah terletak di ridho kedua orang tua, atau dengan kata lain seorang anak semestinya berbakti pada orang tua (ibu).

Nasehat yang disampaikan pencipta lagu dengan memunculkan perbandingan kondisi realitas sosial budaya yang dipaparkan sebelumnya merupakan rangkaian nilai-nilai yang diharapkan dapat memengaruhi pola pikir, tindakan dan perilaku seorang anak agar menghargai jasa-jasa dan senantiasa berbakti pada orang 
tua (ibu). Nilai-nilai yang mendasari perubahan pola pikir seorang anak agar menghargai jasa-jasa seorang ibu dapat diidentifikasi, sebagai berikut:

a. Syarak atau Agama; nilai-nilai tersebut merupakan interpretasi dari kondisi realitas yang menggambarkan ketika seorang ibu sedang dalam keadaan susah payah seperti orang yang sedang menyabung nyawa dan bersimbahkan darah dalam mulai dari proses mengandung hingga saat-saat melahirkan seorang anak tetap berserah diri pada Yang Maha Kuasa.

b. Cinto Ranah Minang; nilai-nilai tersebut merupakan interpretasi dari tema lagu yang menceritakan tentang nasib ibu yang sedang hamil hingga melahirkan. Adat Minangkabau terkenal dengan sistem keturunan yang diambil dari garis ibu (matrilinial). Sistem matrilinial tersebut secara langsung mengarahkan seseorang (orang Minang) pada rasa cinta kampung halaman.

c. Kesabaran; nilai-nilai tersebut merupakan interpretasi dari segenap pikiran, tindakan, dan perilaku seorang ibu (bundo) dengan berbagai rintangan dan kendala yang dirasakan dan dilalui selama mengandung (hamil) hingga melahirkan anak yang tersayang.

d. Keikhlasan; nilai-nilai tersebut merupakan interpretasi dari semua rintangan yang dihadapi oleh seorang ibu dan dilalui tanpa mengeluh, bahkan ikhlas menjalani semua hanya mengharap rido Allah SWT.

e. Keteguhan Hati; nilai-nilai tersebut merupakan interpretasi dari suasana ketegaran dan keteguhan hati seorang ibu dalam kondisi yang susah payah tetap menjalani masa-masa sulit dalam mengandung dan melahirkan seorang anak yang dirindukan selama sembilan bulan sepuluh hari.

Nilai-nilai yang telah diidentifikasi dari proses interpretasi hermeneutik secara multidisipliner terhadap lagu Jaso Mandeh sebelumnya merupakan nilai-nilai yang sangat penting dan bermanfaat bagi pendidikan. Nilai-nilai tersebut memberikan tuntunan, nasehat, didikan, atau dengan kata lain nilai-nilai tersebut memiliki sifat-sifat mendidik (edukatif) generasi muda di lingkungan masyarakat Minangkabau atau peserta didik di lingkungan sekolah.

\section{SIMPULAN}

Proses identifikasi dan analisis hermeneutik secara multidisipliner terhadap Lagu Jaso Mandeh ciptaan Nuskan Syarif dapat mengidentifikasikan 5 (lima) nilai edukatif, yaitu (1) Syarak/agamo, (2) cinto ranah Minang, (3) kesabaran, (4) keikhlasan, dan (5) keteguhan hati. Nilai-nilai edukatif tersebut dapat dijadikan sebagai sarana untuk membangun karakter peserta didik, baik ketika berada di sekolah maupun di lingkungan keluarga atau masyarakat.

Kelima nilai-nilai tersebut sangat berguna bagi pelestarian nilai-nilai adat Minangkabau dan proses aktualisasi nilai-nilai tersebut di lingkungan sekolah, serta dapat dijadikan sebagai sarana edukasi dalam membangun karakter peserta didik, sehingga tercapainya tujuan adat Minangkabau dan tujuan pendidikan, yakni menciptakan peserta didik yang beradat, beradab, dan berkarakter mulia. 


\section{DAFTAR RUJUKAN}

Amir M.S. (2011). Adat Minangkabau: Pola hidup dan tujuan hidup orang Minang. Jakarta: Citra Harta Prima.

Astuti, K.S. (2010, Juni 11-13). Shaping morality through music learning in formal schools in Indonesia: An evaluation study. Artikel dipublikasikan pada Asia Pasific Network for Moral Education 5th dalam Annual Conference Interdisciplinary Moral Education in Asia's Globalising Societies; Concept and Practices. Japan: Nagasaki University

Barendregt, Bart. (2002). The sound of 'longing for home': Redefining a sense of community through Minang popular music. Bijdragen tot de Taal-, Land-en Volkenkunde, 158, No: 3, 411-450: Leiden University

Darwis. (2005, November 28). Tafsir pantun Minang I. Artikel 655. Diambil pada tanggal 22 Januari 2012, dari http://www.cimbuak.net/content/view/6 $\underline{55 / 5 / 1 / 1 /}$

Desyandri. (2014). Peran Seni Musik dalam Pendidikan Multikultural. Jurnal Pembangunan Pendidikan; Fondasi Dan Aplikasi IP PPs UNY, 2(1), 1-11. http://doi.org/http://dx.doi.org/10.21831/jpp fa.v2i1.2613

Desyandri. (2015). Nilai-nilai Edukatif Lagu-lagu Minang untuk Membangun Karakter Peserta Didik (Analisis Hermeneutik). Jurnal Pembangunan Pendidikan: Fondasi Dan Aplikasi, 3(2), 126-141. http://doi.org/http://dx.doi.org/10.21831/jpp fa.v3i2.7566

Desyandri. (2016). Revitalisasi Nilai-nilai Edukatif Lagu-lagu Minang untuk Membangun Karakter Peserta Didik. In Konvensi Nasional Pendidikan Indonesia (KONASPI) VIII (pp. 1941-1951).
Djohan. (2009). Psikologi musik. Cetakan ketiga: Edisi revisi. Yogyakarta: Galang Press

Fithri, W. (2013). Mau kemana Minangkabau? Analisis hermeneutika atas perdebatan Islam dan adat Minangkabau.Yogyakarta: Gre Publishing

Fraser, J. (2011). Pop song as custom: Weddings, ethnicity, and enterpreneurs in West Sumatra. Jurnal Ethnomusicology Sping/Summer, Vol. 55, No. 2, p. 200-228. Ohio: Society for Ethnomusicology

Hajizar. (2012, Maret 13). Lagu Padang Dulu dan Kini. Artikel. Diambil pada tanggal 3 Maret 2014, dari http://albiouna.com/umum/lagu-padangdulu-dan-kini

Hakimy, I. (2004). Rangkaian mustika adat basandi syarak di Minangkabau. Bandung: Rosda Karya

Kuhl, O. (2010). Song Structure and Phenomenology: Text and Music in 'Mr. Tambourine Man'. Jurnal. Oslo: Dept. Of Musicology. Artikel. Diambil pada tanggal 22 Januari 2012, dari http://ssrn.com/abstract $=1532795$ University of Oslo

Merriam, A.P. (1964). The anthropology of music. Evanston, Illionis: Northwestern University Press

Muhadjir, N. (2003). Ilmu pendidikan dan perubahan sosial: Teori pendidikan pelaku sosial kreatif. Yogyakarta. Raka Sarasin

Zainuddin, M. (2010). Pelestarian dan eksistensi dinamis adat Minangkabau. Yogyakarta: Ombak

Zulfadli. (t.t). Lirik lagu Minang lamo. Diambil pada tanggal 22 Januari 2012, dari http://laguminanglamo.wordpress.c 